\title{
A Comparative Study of Teaching the Islamic Prayer
}

\author{
M. Farsi and M. Munro, Member, IACSIT
}

\begin{abstract}
This study implements a Virtual Environment setting to enhance and develop the physical aspects of teaching the Islamic prayer to primary school children, in comparison to traditional forms of teaching through a prayer book and prayer video. An interactive teaching system, the interactive Islamic Prayer (iIP) has been developed for this purpose. Through quantitative analysis of the participants' learning experiences, this study investigates which approach the participants preferred, in terms of their comprehension, participation and overall satisfaction.

The results revealed a higher degree of interaction within the lesson on prayer was found using the iIP compared to the traditional teaching methods, and although some were unfamiliar with the $X$-Box 360 Kinect console, on the whole, they found it fun and educational. The findings also showed that the software was able to focus on lower level thinking skills such as recalling information and memory, as a test of the students' knowledge on the prayer before and after using the software showed a significant improvement in comparison to the other approaches. Recommendations have been given on how to effectively implement this software within these relevant classrooms.
\end{abstract}

Index Terms - Islamic prayer, kinesthetical learning, learning preferences, virtual environments.

\section{INTRODUCTION}

With the continual technological development of Virtual Environments (VE), it has revolution noised how computers and consoles are utilized in daily life. Within the education domain, VE have been used for decades as an adopted method of learning and pedagogy, which includes various functions and uses such as aeronautical training (i.e. flight simulations) or medical procedures [1]. With certain advancements and improvements, not only has there been an expansion in the contexts of legitimate learning environments, but more importantly, in how interaction occurs. This is evident with the advent of appliances such as the Wii and X-Box 360 Kinect, where individuals are now able to engross themselves in a full body experience, whether for entertainment or educational purposes. Interestingly, [2] suggests that although individuals may use such environments for play and entertainment, it is inherent that learning is present. Thus, the concept of integrating interactive learning for a number of teaching purposes and to enhance the various learning styles that a learner adopts is potentially possible. One use of this is for religious practices that require certain movement, more specifically in the Islamic faith and prayer.

Manuscript received October 7, 2014; revised December 7, 2014.

The authors are with the School of Engineering and Computing Sciences, Durham University, UK (e-mail: m.a.r.farsi@durham.ac.uk, malcolm.munro@durham.ac.uk).
This research focuses on using this methodology to devise an interactive learning tool for the purposes of facilitating and motivating individuals to accurately understand and perform the various movements of the Islamic prayer. It further seeks to determine whether this approach is more preferable for primary school children in Saudi Arabia, as opposed to the traditional methods of teaching that takes place in this context, which is through the use of a prayer textbook and prayer video. Thus, the aim of this study is to see how well the various teaching methods can effectively meet the learning styles of the learners (i.e. visual, auditory or kinesthetic).

\section{LITERATURE REVIEW}

\section{A. Learning Styles}

There are various methods that help facilitate learners' ability in constructing new ideas and concepts [3]. What is evident in relation to this is, regardless of class size, it is likely that there are individuals within a classroom environment who learn differently and have a certain preference for their learning style [4]. Three common learning styles have been discussed at length within educational research, which are methods for how learners can perceive information and knowledge in order to facilitate their cognitive learning: visual, auditory or kinesthetic [4], [5]. The visual learner is one who learns more effectively through pictorial or graphical aids (i.e. diagrams, graphs, mind maps etc), whereas, the aural learners' preferences are found by listening to information in the form of lectures or group discussions [6]. Lastly, the kinesthetical learner has an inclination to learn through the use of action or "doing". Reference [7] explains, "the kinesthetical learner wants to know what the movement feels like. The correct feeling becomes the frame of reference in which to compare". Thus, the use of physical interaction and repeated practice of simulations, acting and "hands-on" experiments all assist in building this frame of reference for the learner.

Furthermore, a study conducted on primary and secondary school children by the Specific Diagnostic Studies found that $29 \%$ of learners preferred visual, $34 \%$ preferred auditory means and $37 \%$ classed themselves as kinesthetical learners [8]. A similar survey was conducted by [9] among Kuwaiti university students and found $56 \%$ of them were kinesthetical learners. Accordingly, [10] states that in many cases kinesthetical learners make up $15 \%$ of the student population. These individuals learn better through "action" or being actively/physically involved in the subject that is being studied.

\section{B. Virtual Environment in Education - A "Learn by Doing" Approach}

A Virtual Environment (VE) is defined by [1] as "a 
collection of technologies that allow people to interact efficiently with 3D computer generated models in real-time using their natural senses and skills." A common goal for implementing these environments is to improve motor control skills, making it appropriate to use in practical situations that mimic real-world scenarios [1].

While one would not normally associate computer gaming with developing and acquiring motor skills, the evolution of Gaming Virtual Environments, particularly with the introduction of the Nintendo Wii, has revolutionised how individuals interact and access games. Studies have shown how they can contribute to improve fitness and health, and as a result, gaming companies have launched products that target this particular market. The Wii Balance Board and Wii Fit packages, for example, are amongst Nintendo's highest grossing products and as [1] state, even "the popular Wii Sports package provides simplified versions of tennis, baseball, bowling, golf, and boxing, and evidence is emerging that the Wii platform is contributing to the acquisition of skills in some real sports (e.g.,10-pinbowling)."

A more recent and progressive form of VE is Microsoft's Kinect for XBox 360, which employs markers to recognise, capture, track and decipher a user's movement through infrared technology [11]. This has been described as a "revolution in the making" as the method of interaction between human and computer is no longer bound by tangible objects such as a controller, mouse or keyboard [9]. Moreover, the Kinect is a flexible teaching tool as it allows interaction with multiple users in movement, gestures and voice. While such consoles are primarily aimed at entertainment, researchers are keen to also see how such technology can further be utilised for educational purposes, and in effect to "learn by doing". Reference [12] elaborates on this, stating this method "develops a deeper and more profound knowledge and greater commitment than learning by reading, listening, planning or thinking".

\section{The Saudi Context}

As this study seeks to address the teaching approaches in Saudi Arabia, it is important to discuss the current context in light of this existing literature. The education system in the Kingdom of Saudi Arabia is primarily governed by The Ministry of Education, with The Ministry of Higher Education and The General Organisation for Technical Education \& Vocational Training also supervising other aspects of learning [13]. In terms of the method of teaching, there is a clear contrast between the Saudi schooling system and those found in Western countries like the United Kingdom. The current educational system in Saudi uses traditional teaching theories and methods and, in many cases, sees it as a difficulty in transitioning to more effective theories of learning [14], [15]. That is, whilst many Western countries have begun to deeply integrate constructivist and cognitivist theories within their educational pedagogy and processes, the Saudi system is still very much teacher-centered, with little interaction from the learners. Rote learning is commonplace in Saudi Arabia, which one could assume is as a result of the amount of effort is placed in memorization, particularly in memorizing religious texts such as the Holy Quran [16]. Reference [14] describes this as a typical behaviourist style classroom, whereby students react directly to stimuli but otherwise remain quite passive in their response and attitude towards the teacher and lesson.

During the interviews with a number of teachers, [14] found that their strategy for discussion revolved around certain parameters. For instance, many of the teachers considered discussion to be a one-way transfer of "giving" from the teacher to the student. Additionally, discussions were normally as a result of question and answer, which are often closed questions and did not necessarily encourage deep learning. When relating this methodology to primary schools in Saudi Arabia, the same approach is used to teach the Islamic prayer during their Islamic studies class, which often uses a prayer book that the teacher will read from or the children will be asked to watch a video on the prayer.

\section{THE IIP SOFTWARE DESIGN}

The interactive Islamic Prayer (iIP) software is a learning tool that has been designed for X-box Kinect, and enables the users to immerse themselves into the prayer through physical interaction and active learning. This provides an alternative approach to traditional learning methods, such as using textual or visual resources. More significantly, unlike traditional methods, the iIP software seeks to combine all three learning styles. Thus, in order to design the software around this specific aim, the following Human Computer Interaction (HCI) objectives have been considered:

- Has an appealing interface that makes it easy to use and understand, yet challenging for the users (see Fig. 1 and Fig. 2),

- Is flexible and adaptable with respect to time and place.

- Accurately tracking the synchronous movements from the participant (see Fig. 2).
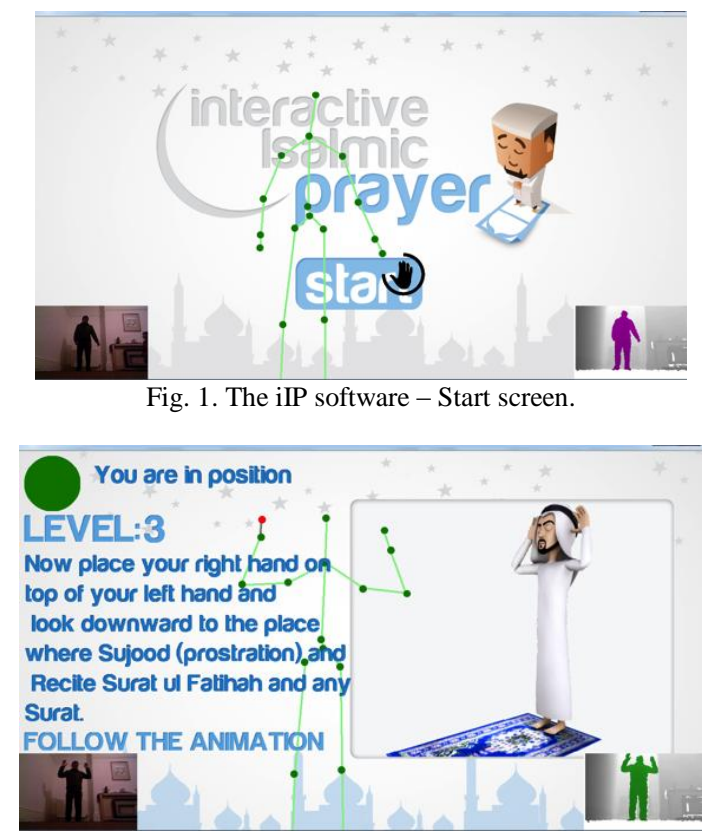

Fig. 2. iIP interface.

\section{Methodology}

The primary objective for this research was to investigate whether the use of interactive virtual environment is a suitable 
platform for learning and can enhance the performance of the Islamic prayer in comparison to other traditional approaches. Therefore, the main research question is as follows: Does the Interactive Islamic Prayer (iIP) Software enhance the development and understanding of the physical aspects of the Islamic prayer in comparison to learning from reading a Prayer Book, or by watching a Prayer Video?

\section{A. Study Design}

This research is primarily quantitative in nature, which will be based on the HCI between the participants and the iIP Software, as well as the interaction involving visual and audio styles of learning (i.e. through a prayer textbook and a prayer video respectively). Moreover, the outlined experiments will serve as the precise instruments to test whether the HCI of the iIP Software enhances and develops learning in comparison to the other methods.

When collecting data from an experiment involving participants, it is crucial that the design compliments the manner in which the data is to be collated. Subsequently, this determines the type of analysis method that will be utilized. There are two common techniques that have been adopted when designing experiments: Between Subjects Design and Within-Subject designs [17] (Fig. 3). The between-group design is where different groups of participants are simultaneously tested against different independent variables, whereas, the within-subject design method is implemented for experiments where the subjects participate and experience every level of the variables [18].

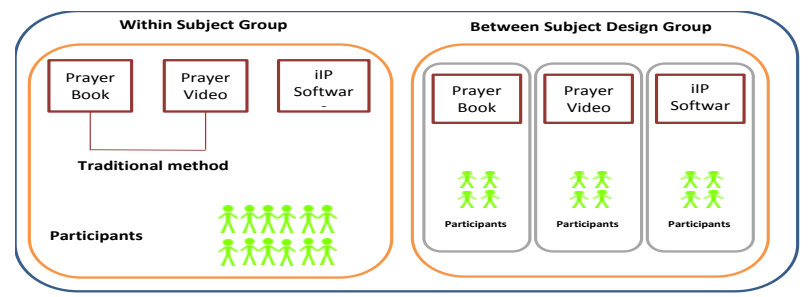

Fig. 3. Between subjects design and within-subject designs.

As a result, the within-subject design method was chosen because of the preferential nature and setup of this experiment Reference [16] further advises that this approach should be adopted because the independent variable is manipulated in each experiment. Consequently, the participants are subjected to all the conditions, which allow the overall analysis of the results to be tested in accordance to any variances that were discovered.

\section{DATA SOURCES}

\section{A. Participants}

This study focused on individuals from a primary school in Saudi Arabia within the age range of 8-11 years old. Although Saudi students are often exposed to the prayer, it will focus the attention on which method will attract and provide a more positive experience for the learner. A total of 30 young persons were involved in the experiment, which was divided equally into three groups. Each of the groups interacted with each method during their Religious Studies class, which allowed them to compare usability and preference. Each class lasted 1 hour where the students were taught according to a particular method (Table I). For the iIP Software class, the students took it in turns to be the subject in front of the whole class.

TABLE I: EXPERIMENT TIMETABLE

\begin{tabular}{|c|c|c|c|}
\hline & Day 1 & Day 2 & Day 3 \\
\hline $\begin{array}{l}\text { Class } 1 \\
(n=10)\end{array}$ & $\begin{array}{l}\text { Prayer } \\
\text { Book }\end{array}$ & $\begin{array}{l}\text { Prayer } \\
\text { Video }\end{array}$ & $\begin{array}{l}\text { iIP } \\
\text { Software }\end{array}$ \\
\hline $\begin{array}{l}\text { Class } 2 \\
(n=10)\end{array}$ & $\begin{array}{l}\text { Prayer } \\
\text { Video }\end{array}$ & $\begin{array}{l}\text { iIP } \\
\text { Software }\end{array}$ & $\begin{array}{l}\text { Prayer } \\
\text { Book }\end{array}$ \\
\hline $\begin{array}{l}\text { Class } 3 \\
(n=10)\end{array}$ & $\begin{array}{l}\text { iIP } \\
\text { Software }\end{array}$ & $\begin{array}{l}\text { Prayer } \\
\text { Book }\end{array}$ & $\begin{array}{l}\text { Prayer } \\
\text { Video }\end{array}$ \\
\hline
\end{tabular}

\section{B. Questionnaires}

A number of questionnaires were administered to all the participants during various stages of the experiment (see Table II). The questionnaires for all three learning methods (prayer book, prayer video and iIP Software) were identical, with the exception of having each question refer specifically to that particular learning method. The purpose for this was to provide a comparison of the learning methods from varying perspectives, features and preferences. This was used to effectively answer the research question for students and teacher, with the questions pertaining specifically to the method that was being analysed.

As the questionnaires were given young learners, a likert scale was applied for ease of use and so that the data provided explicit answers to the questions. The scale consists of four values: Strongly Agree, Agree, Disagree, Strongly Disagree (or for the purpose of children, the use of emoticons: $\odot),(;)$, $\odot, \odot \odot)$, which are given the value 1-4 respectively when inputting the data into statistical analysis software for analysis.

TABLE II: QUESTIONNAIRES ADMINISTERED TO PARTICIPANTS

\begin{tabular}{c|l}
\hline $\begin{array}{c}\text { Students' } \\
\text { Pre-Demographic } \\
\text { Questionnaire }\end{array}$ & $\begin{array}{l}\text { Used to evaluate the learners existing } \\
\text { knowledge of the Islamic prayer by } \\
\text { providing certain demographic information } \\
\text { such as their age, whether they already } \\
\text { know how to pray and how they have learnt } \\
\text { the prayer }\end{array}$ \\
\hline $\begin{array}{c}\text { Students' } \\
\text { Post-Questionnaire }\end{array}$ & $\begin{array}{l}\text { Preferences relating to the specific learning } \\
\text { style that the participants complete. }\end{array}$ \\
\hline \multirow{3}{*}{ Final Questionnaire } & $\begin{array}{l}\text { When participants have experienced and } \\
\text { completed all three learning styles, the final } \\
\text { questionnaire is administered. This } \\
\text { questionnaire will be used specifically to } \\
\text { rank the three methods in terms of their } \\
\text { preference and whether or not they are } \\
\text { effective tools for teaching and learning. }\end{array}$ \\
\hline
\end{tabular}

\section{Pre and Post-Tests}

In addition to the questionnaires, the students also completed a pre and post-test, consisting of images of specific prayer positions and multiple-choice questions. The aim was to test their existing knowledge of the prayer. The post-test was given at the end of each groups' first session, which was then compared with the pre-test, allowing the researcher to evaluate whether any learning had taken place. It may also imply that a particular learning method was effective in teaching the specific movements for the prayer if it showed an improvement in the learners' answers. 


\section{Observations}

Observations of the students were also conducted in order to examine the extent by which engagement and interaction were demonstrated by the learners within each learning method. The observations took place throughout each session by the researcher, using the same classroom layout and criteria.

\section{RESULTS}

Upon completion of the various experiments, the data was collated and analysed accordingly. What follows is an overview of the results in relation to each of the questionnaires that was administered.

\section{A. Post-Session Questionnaires}

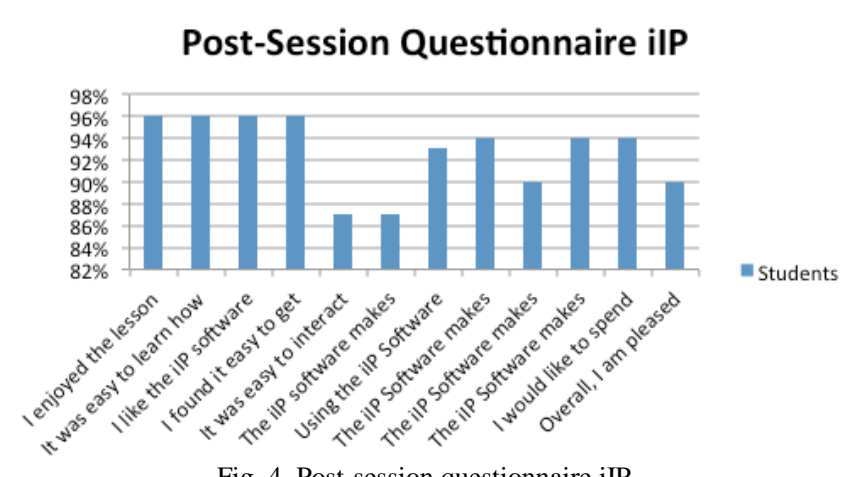

Fig. 4. Post-session questionnaire iIP.

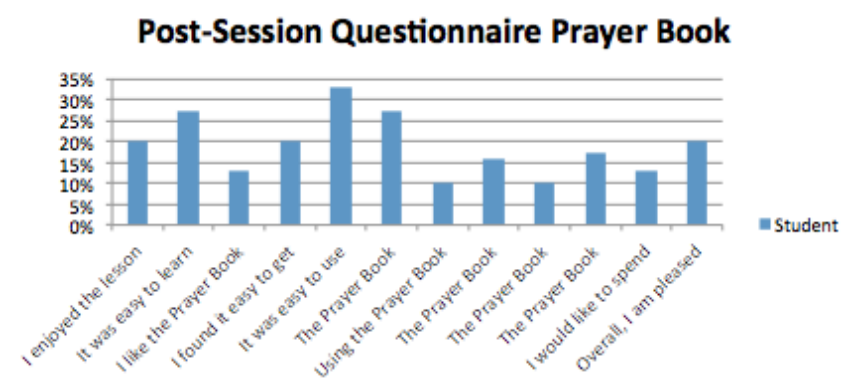

Fig. 5. Post-session questionnaire prayer book.

Post-Session Questionnaire Prayer Video

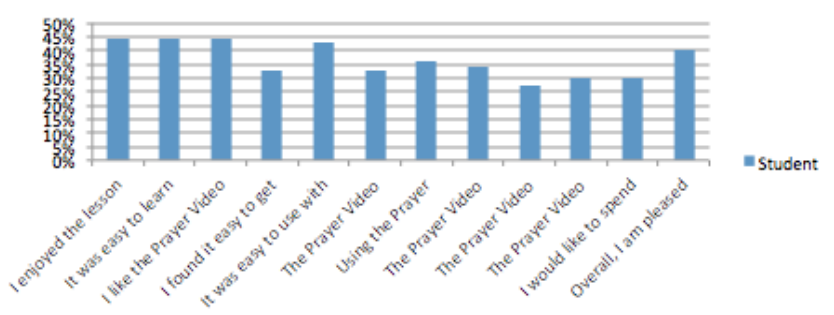

Fig. 6. Post-session questionnaire prayer video.

The Post-Session Questionnaires relating to each of the learning styles all revealed that students were significantly more inclined towards the iIP software (Fig. 4), stating they found the lesson more enjoyable (96\%), easier to learn the prayer through this method (96\%), an overall preference to it $(96 \%)$, it enabled them to get more involved in the lesson $(96 \%)$, easier to interact with $(87 \%)$, provided a better understanding of the prayer $(87 \%)$, created a more exciting and interesting learning environment $(93 \%)$ was more relaxed (94\%), gave them more confident in their prayer $(90 \%)$, encouraged them to pray more $(94 \%)$, made them them want to spend more time using it (94\%) and lastly, an overall satisfaction with the IIP software $(90 \%)$. This can be compared to the other approaches, which scored significantly lower (Fig. 5 and Fig. 6).

\section{B. Final Questionnaire and Post-Test}

When asking the participants to give their final choice over which learning approach they preferred the most, the results further reinforced these findings, indicating the iIP software was regarded as a better approach from a number of perspectives (Fig. 7). This included the overall HCI, effectiveness as a learning tool and their personal preference. In addition, this was supported by the post-test questionnaire, which showed learners had improved considerably in answering the correct prayer positions, and was more effective than the other methods (Table III and Table IV).

\section{Which method do you prefer the most}

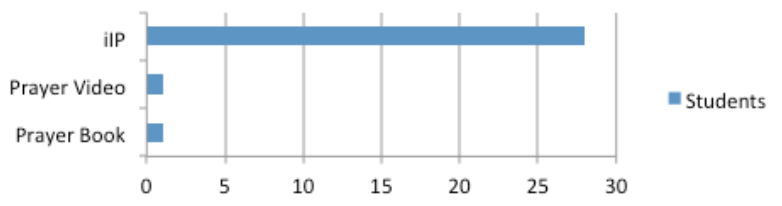

Fig. 7. Participants' responses over their preferred approach.

TABLE III: AVERAgE SCORE FOR CORRECT ANSWERS IN PRE-TEST

\begin{tabular}{|l|l|}
\hline Group Pre-Test & $\begin{array}{l}\text { Average score for correct answers } \\
\text { given }\end{array}$ \\
\hline iIP & $30 \%$ \\
\hline Prayer Book & $32 \%$ \\
\hline Prayer Video & $31 \%$ \\
\hline
\end{tabular}

TABLE IV: AVERAGE SCORE FOR CORRECT ANSWERS IN POST-TEST

\begin{tabular}{|l|l|}
\hline Group Post-Test & $\begin{array}{l}\text { Average score for correct answers } \\
\text { given }\end{array}$ \\
\hline iIP & $92 \%$ \\
\hline Prayer Book & $60 \%$ \\
\hline Prayer Video & $62 \%$ \\
\hline
\end{tabular}

\section{DISCUSSION}

The feedback that was given from both the students and teachers provided a greater insight into how the iIP software can be used as an effective learning tool within classrooms. As the results indicate, an overall approval and preference by the participants to use the iIP software was found, which supports the views of those who advocate the kinesthetical style of "learning by doing", such as [1] and [11]. However, it should be noted that the various elements of the software, such as the instructional avatar and audio instructions, still allowed those learners of other styles (i.e. visual and auditory) to also be engaged. In comparison to the other approaches, it is evident that teaching through the use of a prayer book or watching a prayer video catered specifically to a particular learning style (i.e. prayer book to visual and prayer video to visual/auditory). Subsequently, this can restrict and disengage learners who adopt other styles like the kinesthetical way of learning.

It was also evident throughout the experiment that the students had an overall effective learning experience and wished to continue using this approach even after the session 
was over. This demonstrates that the software could be viewed as a game for young people, whilst also being educational.

This learning experience could also be viewed from two different perspectives: the learners' overall preference and whether or not it actually improved their understanding of a particular subject matter. Both these were achieved using the iIP software, as the participants graded the iIP software to be a better approach than the traditional methods based on its practical application, attractiveness and fun features, as well as its ability to effectively engage the learners in becoming more involved in the session.

With regard to how well the iIP software improved the learners understanding, then this was apparent from the pre and post-tests, which illustrated that, although students felt they had a good understanding of the prayer positions, in reality this was not the case; however, through the use of the iIP software, a considerable improvement in their knowledge of the positions was made, even more so than the tests after using the traditional methods (book and video). In addition, this method of "learning by doing" from the iIP software enabled those who were watching the learner using the Kinect to learn from any mistakes they made, so using this in a classroom setting proved to be beneficial for the overall group.

\section{CONCLUSION}

This paper addresses the findings from using the iIP software in the classroom environment. Whilst it is evident that the use of virtual environments is prevalent within the context of gaming, its use in education is also becoming increasingly popular. The experiment generated positive results from the participants, who found the software to be useful in their goal of learning the prayer. It was observed that the "learning by doing" approach stimulated the learners' interaction and engagement, more so than the other approaches, and also catered for the various learning styles.

\section{ACKNOWLEDGMENT}

I would like to express my gratitude to the Ministry of Higher Education in Saudi Arabia for sponsoring my scholarship for this research "A Comparative Study of Teaching the Islamic Prayer". And I would like to express my gratitude my $\mathrm{PhD}$ supervisor, Malcolm Munro for his continuous support.

\section{REFERENCES}

[1] H. C. Miles, S. R. Pop, S. J. Watt, G. P. Lawrence, and N. W. John, “A review of virtual environments for training in ball sports," Computers \& Graphics, vol. 36, pp. 714-726, 2012.

[2] L. P. Rieber, "Seriously considering play: Designing interactive learning environments based on the blending of microworlds, simulations, and games," Educational Technology Research and Development, vol. 44, pp. 43-58, 1996.

[3] J. Biggs and C. Tang, "Teaching for quality learning at university Berkshire," UK, Open University, 2003.

[4] R. M. Felder and L. K. Silverman, "Learning and teaching styles in engineering education," Engineering Education, vol. 78, pp. 674-681, 1988.

[5] J. B. Miller, "Examining the interplay between constructivism and different learning styles," 2007.

[6] P. Miller, "Learning styles: The multimedia of the mind," 2001.

[7] N. D. Fleming, Teaching and Learning Styles: VARK Strategies: ND Fleming, 2006.

[8] C. A. Coker, "Accommodating students' learning styles in physical education," Journal of Physical Education, Recreation \& Dance, vol 67, pp. 66-68, 1996.

[9] A. Zeid, A. Taqi, O. ElKhatib, T. Al-Yaseen, and T. AlMayyan, "KinEd: A kinect-based e-learning platform to enhance collaborative and kinesthetic learning," International Journal of Computer Applications, vol. 88, pp. 1-6, 2014.

[10] H.-M. J. Hsu, "The potential of kinect in education," International Journal of Information and Education Technology, vol. 1, pp. 365-370, 2011.

[11] D. DePriest and K. Barilovits, "LIVE: Xbox Kinectâ@ s virtual realities to learning games," in Proc. TCC-Teaching Colleges and Community Worldwide Online Conference, 2011, pp. 48-54.

[12] R. DuFour, R. Eaker, and T. Many, Learning by Doing: A Handbook for Professional Learning Communities at Work, IN: Solution Tree Press Bloomington, 2010.

[13] A.-A. Ramadan, Education in the Kingdom of Saudi Arabia, S.A.: The New National Publisher \& Distributers, 1994.

[14] M. A.-T. Al-Qurashi, "The methods of reconstruction of education in the graduate schools in Saudi Arabia universities," presented at Symposium of Graduate Schools in Saudi Arabia Universities: Future Trends, King Abdul-Aziz University, April 17-18, 2001.

[15] M. I. Jamjoom, "Female Islamic studies teachers in Saudi Arabia: A phenomenological study," Teaching and Teacher Education, vol. 26, pp. 547-558, 2010.

[16] E. A. Doumato, "Education in Saudi Arabia: Gender, jobs, and the price of religion," Women and Globalization in the Arab Middle East, pp. 239-258, 2003.

[17] A. Field and G. J. Hole, "How to design and report experiments," Sage, 2002.

[18] D. C. Montgomery, Design and Analysis of Experiments, John Wiley \& Sons, 2008

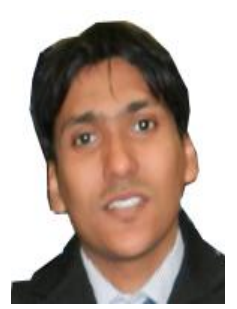

Mohammed Farsi is interested in the field of computer science. After completing his bachelor's degree at King AbdulAziz University (Saudi Arabia), he pursued a profession in teaching computing at high school level. Building upon this experience, he was awarded a scholarship to complete his masters (MSc) in computer science at Newcastle University (England), which led to various projects and work that he has undertaken. These include designing and incorporating databases in web applications using $\mathrm{PhP}$, being part of a team that designed a multi-touch surface "airplane cockpit", the design, programming and implementation of a baggage handling system and the design and programming for a "Phone Company Application". As part of his MSc dissertation project, he also designed, programmed and implemented a "Computer Algebra System (CAS) Tool", which solved differentiation equations. He is currently in the process of completing his $\mathrm{PhD}$ in computer science at Durham University (England), which is based on a combination of all his previous experience and knowledge in education and e-learning. Subsequently, the focus of his research is the development of software to enhance the learning experience for the Islamic Prayer. 